\title{
A história da doutrina da incidencia
}

\section{Teotônio Monteiro de Barros Filho}

I - A historia da doutrina da incidencia se divide em dois grandes períodos. O marco divisor é a obra de AdaM Sмiтн e a teoria dos fisiocratas.

Num e noutro desses dois periodos, múltiplas teorias se apresentaram, algumas com tais ligações recíprocas, que se faz dificil classificá-las. Ás que surgiram no primeiro peŕiodo se dá o nome genérico de "teorias primitivas"; ás do segundo, "teorias modernas".

II - No primeiro período, isto é, desde os começos do século XVII, até o advento de Adam SmITH e dos fisiocratas, a literatura foi abundante principalmente na Inglaterra. Manifestou-se por meio de opúsculos e panfletos, da autoria de homens políticos, comerciantes e alguns economistas, tendo em vista não propriamente o objetivo imediato de estudar a incidencia em si, mas o de examinar a conveniencia de certos tipos de impostos, sob o seu aspeto político e econômico.

Até o inicio do século XVII, a tributação era mais ou menos rudimentar, sob o ponto de vista dos princípios. Afóra a influencia romana, presente na figura de alguns velhos impostos, que conseguiram atravessar o periodo medieval, e tambem alguns outros oriundos do período barbárico, a imposição predominante era a fundiaria, na qual se haviam transformado as tentativas de lançamento de impostos sobre a propriedade em geral.

Ao que parece, terá sido HobBes o primeiro escritor a sugerir de modo explícito a despesa do individuo como um 
critério de tributação. Um imposto direto sôbre as mercadorias, que, sob o nome de excise, devia ser pago na Inglaterra por produtores e comerciantes, entrou a ser aplicado, fazendo-se mais ou menos aceito como um modo prático, facil e suficiente de obterem-se receitas para o Estado. Entendia-se geralmente que esse tributo era repercutido pelos produtores e comerciantes sôbre os consumidores, tornandose um imposto indireto de consumo.

Entretanto, dentro de algum tempo, começaram a ser levantadas dúvidas sobre a conveniencia de tal imposto, surgindo resistencias. Elas se avolumaram quando, no segundo quarto do século XVIII, WaLpole organizou o seu plano geral de tributação dos consumos, conhecido sob o nome de excise scheme, em torno do qual se estabeleceu a mais acesa polêmica. Nesta, empenharam-se economistas, parlamentares, proprietarios territoriais, comerciantes, homens práticos da vida, manifestando uns os seus pontos de vista puramente especulativos, enquanto que outros exprimiam sem dúvida idéias que refletiam interesses pessoais ou de classe.

A verdade, porém, é que dessa discussão, então instaurada em torno do imposto de consumo, foram surgindo, por via de consequencia, e como corolários de argumentos cxpendidos em favor ou contra o excise, vários conceitos de carater doutrinário, relativos ao fenômeno da incidencia.

Com o objetivo de demonstrar óra que o imposto de consumo era bom, porque, embóra repercutindo sôbre os consumidores, deixava isentos praticamente os pobres trabalhadores; óra que ele incidia de modo geral sôbre todos os consumidores, razão pela qual era justo; óra que ele, em última análise, era suportado pelos proprietários territoriais; óra, finalmente, que ele não repercutia, sendo um gravame dos próprios produtores e comerciantes percutidos, -... a verdade é que foi realizada, no fundo, uma pesquiza sobre a incidencia. Pensando discutir as vantagens e desvantagens dos altos e baixos impostos, ou dos altos e baixos salários, ou ainda a justiça ou injustiça do excise, o que realmente se produziu então foi, através de um longo e 
prolixo debate, a coleta de uma série de observações e de dados para o esclarecimento da incidencia, embóra esse não fosse o objetivo direto da discussão.

E o sentimento popular, formado graças ao debate amplo e público do assunto, cristalizou-se em torno da tese segundo a qual a repercussão do excise efetivamente se ope rava sobre os consumidores, aumentando o fardo tributário da massa dos trabalhadores.

Mas, ao lado desse primeiro grupo de teorias que versavam os impostos de consumo, o debate do plano. Walpole teve o condão de despertar uma série de outros pontos de vista, que, no fundo, se relacionavam todos com o fenômeno da incidencia, dando lugar a outras tantas teorias.

Assim foi que surgiram -várias outras teses, ligadas á conveniencia de se implantar um regime de unidade de imposto, mas imposto que, por sua natureza, não se pudesse repercutir. E então, tentados pelas conhecidas vantagens de simplicidade que o imposto único apresenta, uns preconizaram a substituição de todos os impostos de consumo por uma imposição sobre os artigos de luxo exclusivamente; outros aventaram que se tomassem as casas para base de cálculo das despesas de que eram capazes os contribuintes, instituindo-se um imposto único sobre as mesmas, sendo essa fórmula, posteriormente, alterada para uma imposição sôbre as janelas; -outros, alterando o critério da despesa como base da imposição, sugeriam uma imposição única e direta da terra, adotando assim o critério da propriedade como base para o cálculo (Locke e outros).

Afinal, completando os termos do debate, mais dois grupos se desenharam: um o daqueles que preconizavam uma volta á tributação da propriedade em geral (não só a fundiária), sugerindo principalmente impostos sobre os mutwos de dinheiro, com o fim de atingir a usura; outro, o grupo eclético, que se batia por uma tributação que, fundada em dois ou mais dos critérios precedentemente apontados, fosse mais completa e mais apta a colimar os seus fins. 
A verdade é que, segundo nóta Seligman, embora faltassem nessa época certos conhecimentos de princípios básicos da Economia Política, notadamente uma teoria exata da distribuição da riqueza, que só surgiram com Adam Smith, Ricardo e os fisiocratas, a discussão do imposto de consumo e das demais soluções propostas ao problema tributário, fez fez nascer desde então quasi todas as teorias concebiveis a respeito da incidência:

a) a teoria da não repercussão, segundo a qual o imposto incide sobre o próprio percutido;

b) a teoria segundo a qual o imposto, qualquer que seja, em última análise, incide sôbre os proprietários da terra;

c) a teoria que sustentava a repercussão sôbre os consumidores, óra de modo geral; óra de modo restrito, ficando isentos os pobres (porque eles, por sua vez, repercutiam sôbre os empregadores, sob a forma de aumento de salários).

Por outro lado, desse debate surgiram ainda alguns conceitos que, embora então apenas esboçados, ocupam hoje importante lugar entre os princípios que orientam a incidência nos sistemas tributários modernos. Esses conceitos são principalmente quatro:

1) enquanto se discutia o imposto de consumo, aqueles que the eram adversos, entre as acusações com que o fulminavam, acentuavam o fato da sua injustiça, alegando que ele se distribuia iniquamente, uma vez que pesava de módo igual sôbre ricos e pobres, sem levar em conta o poder econômico do consumidor. Nesta idéia estava, sem dúvida, o germem do princípio da $c a-$ pacidade contributiva, que hoje informa o sistema impositivo de todos os povos civilizados; 
2) debatendo as vantagens $\mathrm{e}$ as desvantagens dos altos e baixos salários, mais de uma vez foi invocada por este ou aquele escritor a idéia da inconveniência de se gravar a renda exclusiva do trabalho. Essa idéia havia de gerar, na finança hodierna, a tendência para a isenção do mínimo de existência;

3) ainda esse mesmo debate sôbre os salários, em ocasiões diversas, fez lembrar a idéia de se utilizarem impostos para compelir a redução do nivel de salários, cuja altitude se considerou, por parte de alguns, como nociva aos interesses da indústria nacional, em competição com a estrangeira. Ora, aí já se póde vêr claramente a tentativa de atribuir aos impostos funções outras que não as puramente fiscais, isto é, funções sociais;

4) finalmente, mais de um autor vislumbrou a influência que póde ter, no fenômeno da incidência, o fato de ser possivel ao produtor diminuir o custo através do aumento da produção, graças a uma melhoria da técnica industrial. Esta observação foi a origem do esclarecimento científico do fenômeno da rejeição do imposto, a que SEligman dá o nome de transformação do imposto, o qual é intimamente ligado ao fato da incidência.

Este o balanço do ativo de conhecimentos legados á Economia e á Finança pelas chamadas "teorias primitivas".

Passemos agora um rápido golpe de vista pelo segundo período da história da incidência, no qual se defrontam as várias teorias a que Seligman dá o nome de "teorias modernas". 
Abre-se ele com a teoria dos fisiocratas, entre os quais se destacam Quesnay e Turgot, seguindo-se logo a Escola dos Economistas, com Adam Smith e Ricardo, cujas idéias sôbre a incidência são conhecidas pelo nome de teoria absoluta, por causa do carater de rigidez das suas generalizações e abstrações, principalmente no que tóca a Ricardo.

Como já vimos, o que entravara anteriormente a expansão dos conhecimentos sôbre a incidência fôra a carência de idéias claras sôbre a repartição da riqueza. Ora, o grande mérito quer dos fisiocratas, quer dos estudos de Adam Smith e de Ricardo, foi o de abrirem a via para novos conhecimentos nesse terreno, possibilitando, dest'arte, investigações mais profundas e mais sistemáticas sôbre a incidência.

Quaisquer que sejam as criticas e correções posteriores, que as mais modernas idéias tenham trazido aos trabalhos Fisiocratas e dos Economistas, a verdade é que eles foram verdadeiros pioneiros.

Deixando de parte a chamada teoria agnóstica do imposto, formulada por Abolph Held e alguns outros autores, que afirmavam a impossibilidade de quaisquer conclusões exatas a respeito da incidência, por causa da enorme complexidade dos efeitos dos impostos, verifica-se, logo depois de Adam Smith e de Ricardo, o aparecimento de uma corrente de idéias que estava destinada a fazer certa fortuna.

Foi a teoria da difusão igual do imposto. Lançaramna Verri, Andrew Hamilton e principalmente Canard. Estes assentaram a corrente a que, dentro dessa teoria, se deu o nome de otimista. Para eles a questão de saber qual seria o contribuinte mais acertadamente percutivel era de importância secundária, porque, em última análise, quaisquer que fossem os impostos, assim como quaisquer que fossem os contribuintes primeiramente atingidos, o certo é que, com o tempo, o montante da imposição acabava difundindo-se de um modo igual pela massa dos contribuintes, de maneira a diluir-se por completo e a acabar não pesando em ninguem. Esses autores, especialmente 
CANard, eram muito amigos dos similes com fenômenos físicos para demonstrar as suas teorias, comparando o lançamento do imposto com o de um liquido num sistema de vasos comunicantes, ou mesmo com o processo circulatório do organismo humano. Mas havia tambem, entre os que aceitavam a teoria da difusão igual, os chamados pessimistas, que tinham em Proudhon, o anarquista, a sua mais alta expressão. Eles aceitavam o fato da difusão igual do imposto, embora achassem que ela não côrrigia as iniquidades da imposição, porque tais iniquidades não residiam no imposto em si - mal necessário, - mas resultavam da ordem econômico-social vigente.

Por seu lado, tambem os socialistas apresentaram seus pontos de vista sôbre a incidência, chefiados por Lassalle. A teoria socialista do imposto sustentava que, afóra o caso dos impostos sôbre a terra e sôbre a renda pessoal, todos os demais acabavam por incidir sôbre o trabalho.

Cabe aqui referencia á teoria da capitalização. Seligman assim apresenta o seu ponto de partida: "na medida em que um imposto fundiario fere de modo exclusivo o proprietario do sólo, observa-se que o valor desse sólo fica diminuido em importancia igual ao valor capitalisado do imposto". Por isso mesmo, "o individuo que compra um bem não paga senão o seu valor já diminuido". (Seligman, - “Theorie de la Repercussion et de l'Incidence de l'Impôt", Paris, 1910, Giard \& Brière, editores, pg. 238). Fundada nestes dados de observação, a teoria da capitalização procura assentar varias conclusões sobre o fenômeno da incidencia em geral (não sómente sobre a incidencia dos impostos fundiarios), e tambem sobre efeitos econômicos de impostos varios.

São ainda de se mencionar os autores que procuraram introduzir na pesquiza da incidência os métodos matemáticos, chegando por vezes a resultados deveras interessantes. Foram principalmente Cournot, Wicksel, Edgeworth, PanTAlEONi e outros. Expuzeram a chamada teoria quantitativa ou matemática do imposto. 
Finalmente, como no período anterior, temos uma teoria eclética da incidência. O seu nome está a dizer que ela é formada por um grupo de autores que, embora apresentando entre si variações de pormenor, têm entretanto a comum carateristica de procurarem utilizar, nos seus estudos atuais do fenômeno, quanto de útil e de verdadeiro restou das investigações feitas nas várias teorias pretéritas. Nos dias que correm a mais completa exposição de doutrinas sôbre a incidência, com base em fatos práticos e nas verdades sobejantes e já comprovadas das antigas e precedentes teorias, é apresentada por Edwin Seligman, na sua obra conhecidíssima intitulada "Shifting and Incidence in Taxation". Dado o seu método e ainda tendo-se em conta os pontos teóricos em que assenta as suas opinióes, não nos pareceria errado classificá-lo tambem como um eclético.

E' este o resumo da história da doutrina da incidência.

Nota: - A historia da doutrina da incidencia apresenta dificuladades ao estudo, por falta de bibliografia. A obra de Seligman, atraz citada, surge neste campo com inteira exclusividade. Entretanto, trabalho eminentemente tecnico, que reclama ao leitor a posse de conhecimentos aprofundados e especialisados, ela é, alem de longa, de uma leitura bastante complexa. Assim, ao resumirmos essa obra do eminente economista e financista americano, tivemos em vista oferecer aos alunos desta Faculdade, e a todos quantos a materia possa interessar, um apanhado rapido e fiel, que servirá, pelo menos, de roteiro seguro para mais amplas investigações. 